\title{
Multiple Deletions of Mitochondrial DNA in Several Tissues of a Patient with Severe Retarded Depression and Familial Progressive External Ophthalmoplegia
}

\author{
Anu Suomalainen, * Anna Majander," Matti Haltia," Hannu Somer," Jouko Lönnqvist," \\ Marja-Liisa Savontaus, ${ }^{* *}$ and Leena Peltonen* \\ ${ }^{*}$ Department of Human Molecular Genetics, National Public Health Institute, 00300 Helsinki; ${ }^{\ddagger}$ Department of Medical Chemistry, \\ University of Helsinki, 00170 Helsinki; ${ }^{\S}$ Department of Pathology, University of Helsinki, 00300 Helsinki; "Department of Neurology, \\ University of Helsinki, 00290 Helsinki; ' Department of Mental Health, National Public Health Institute, $00300 \mathrm{Helsinki;}$ \\ and ${ }^{* *}$ Department of Medical Genetics, University of Turku, 20520 Turku, Finland
}

\begin{abstract}
Multiple deletions of mitochondrial DNA (mtDNA) have recently been reported in familial progressive external ophthalmoplegia (PEO), in a case of progressive encephalomyopathy, and in inherited recurrent myoglobinuria. The inheritance of familial PEO has been autosomal dominant, which indicates that a mutation in an unknown nuclear gene results in several mtDNA deletions of different sizes in these patients. We report a patient with autosomal dominant $\mathrm{PEO}$, whose major clinical symptom, however, was severe retarded depression. The morphological analyses of the tissue samples derived from autopsy showed various abnormalities in the mitochondria in all the tissues studied. The activities of the respiratory chain enzymes encoded by mtDNA were remarkably reduced in the skeletal muscle. The mtDNA analyses confirmed that besides myopathy, this patient had a multisystem disorder with widespread distribution of multiple deletions of mtDNA. The highest percentage of mutated mtDNA was found in the brain, skeletal muscle and the heart, the relative quantity of mutated mtDNA correlating to the severity of the clinical symptoms. (J. Clin. Invest. 1992. 90:61-66.) Key words: encephalopathy • myopathy • oxidative phosphorylation • respiratory chain • slip replication
\end{abstract}

\section{Introduction}

The mitochondria are ruled by two different genomes, the nuclear and the mitochondrial. The mitochondrial genotype is the result of several thousand mitochondrial DNA (mtDNA) ${ }^{1}$ copies in each cell. Human mtDNA is a circular doublestranded molecule of $16.6 \mathrm{~kb}$. It encodes 13 subunits of the respiratory chain enzymes, as well as the mitochondrial ribosomal and transfer RNAs. Most of the mitochondrial proteins

Address reprint requests to Dr. Suomalainen, Department of Human Molecular Genetics, National Public Health Institute, Mannerheimintie 166, SF-00300 Helsinki, Finland.

Received for publication 15 July 1991 and in revised form 17 January 1992.

1. Abbreviations used in this paper: $\mathrm{CK}$, creatine kinase; $\mathrm{CK}-\mathrm{BB}$ and CK-MB, creatine kinase isoenzymes, $\mathrm{BB}$ mostly brain-specific and $\mathrm{MB}$ mostly myocardium-specific; mtDNA, mitochondrial DNA; nt, nucleotide; PCR, polymerase chain reaction; PEO, progressive external ophthalmoplegia; RRF, ragged red fibers.

J. Clin. Invest.

(C) The American Society for Clinical Investigation, Inc.

0021-9738/92/07/0061/06 \$2.00

Volume 90, July 1992, 61-66 are, however, encoded by nuclear genes. Consequently a mutation in either genome may result in mitochondrial dysfunction.

Mutations of mtDNA have been associated with several human diseases ranging from mild myopathies to severe multisystem disorders. Large single deletions were first reported in mitochondrial myopathies (1) and have been later shown to exist in progressive external ophthalmoplegia (PEO) $(2,3)$, Kearns-Sayre syndrome $(3,4)$, and Pearson's syndrome (5). Multiple deletions of mtDNA have been reported in familial PEO (6-8), familial mitochondrial myopathy (9), a case of progressive encephalomyopathy (10), and in inherited recurrent myoglobinuria (11).

MtDNA is inherited through the maternal lineage. However, only the diseases associated with point mutations of mtDNA show matrilinear transmission. Single deletions are mostly sporadic with variable tissue involvement, which suggests the mutations to be of somatic origin. However, some reports of maternally inherited single deletions of mtDNA exist in the literature $(2,12)$. The PEO families $(6-8)$ with multiple deletions of different sizes show an autosomal dominant mode of transmission. This could be explained by a factor encoded by nuclear genes that somehow disturbs the interaction between the nucleus and mitochondria resulting in multiple mtDNA deletions in these patients (6-8).

To date, multiple deletions of mtDNA have been found only in the muscle (6-8) of the patients with autosomal dominant PEO. We report here molecular genetic, morphological, and biochemical studies of an autopsied patient who suffered from autosomal dominant PEO and major depressive episodes with severe psychomotor retardation. Multiple deletions of mtDNA were found in several tissues analyzed, the most severely affected tissues being the brain, heart, and the skeletal muscle.

\section{Methods}

\section{Case report}

The patient was the seventh of 10 children of unrelated parents (Fig. 1). Her development was normal in childhood. From the age of $19 \mathrm{yr}$ onward she suffered from successive episodes of severe psychomotor retardation and depressive mood with apathy, mutism, fatigue, insomnia, and negativism as well as loss of initiative and appetite, fulfilling the criteria of major depressive disorder (DSM-III-R). The depression was often accompanied by long periods of amenorrhoea. The patient was treated with electric and insulin shocks as well as with antidepressive drugs. Between the depressive episodes the patient worked as a housemaid and was considered healthy by her siblings. After the age of $50 \mathrm{yr}$ the depression changed to a more chronic stage, and she became unable to work. 


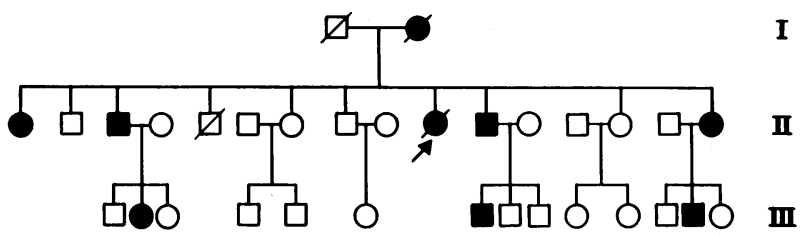

Figure 1. The autosomal dominant inheritance of the PEO. (๑) PEO patients; (O) healthy members of the family. Arrow: the proband.

In the physical examination at the age of $52 \mathrm{yr}$ the patient's height was $148 \mathrm{~cm}$ and weight $32 \mathrm{~kg}$. She had bilateral ptosis, first detected at the age of $29 \mathrm{yr}$, and limitation of eye movements in all directions. She had generalized muscle weakness corresponding to the reduction of muscle bulk. The histochemical and electron microscopic study of a muscle biopsy specimen established the diagnosis of mitochondrial myopathy.

At the age of $60 \mathrm{yr}$ the patient was admitted to hospital because of chest pain and dyspnoea. She was cachectic and suffered from delusions and paranoia. Serum creatine kinase (CK) value was $1.962 \mathrm{U} /$ liter (normal < $150 \mathrm{U} /$ liter) of which CK-MB comprised $12 \%$ and CKBB 7\%. Serum lactate dehydrogenase activity was $1.051 \mathrm{U} /$ liter with an increase predominantly in the lactate dehydrogenase 1 fraction. The enzyme activities returned to normal within a few days, but the CK$\mathrm{MB}$ and - $\mathrm{BB}$ isoenzymes remained detectable. However, repeated electrocardiogram examinations did not show any signs of myocardial ischemia. In 1 wk the patient was resuscitated twice from ventricular fibrillation; then she became comatose and died.

The patient's mother had progressive ptosis, and four of the siblings and three of their offspring suffer from PEO and muscle weakness (Fig. 1). One affected brother has had cardiac arrhythmias. The eldest sister with PEO experienced a sudden respiratory insufficiency due to weakness of respiratory muscles and is dependent on assisted ventilation. Although the psychiatric examination of the family members has not yet been completed, a tendency to depressive mood, e.g., suicide attempts and withdrawal from the community, has been reported in the affected individuals. The proband was the only one receiving psychiatric treatment.

\section{Morphology}

Muscle biopsy findings. A biopsy specimen taken from the vastus lateralis muscle showed scattered ragged red fibers (RRF) in cryostat sections stained by Gomori's trichrome method. Electron micrographs revealed large subsarcolemmal accumulations of abnormal mitochondria, many of which contained electron-dense inclusion bodies of the "parking lot" type (Fig. $2 a$, inset).

Autopsy findings. At autopsy, performed $3 \mathrm{~h}$ postmortem, no macroscopic abnormalities were noted in the brain or heart apart from slight cerebral edema. In particular, there was no evidence of cardiac infarction and the coronary arteries were intact. The liver was fatty. The skeletal muscle mass was scanty and the extraocular muscles were reduced to small strands of yellowish tissue, hard to distinguish from the surrounding fat.

At light microscopic examination of routine paraffin sections there was evidence of acute neuronal damage of the anoxic-ischemic type of the left hippocampal Sommer sector and some neocortical areas as well as moderate loss of cerebellar Purkinje cells. In addition, fatty change of the liver was noted. In cryostat sections from the extraocular muscles most muscle fibers had been destroyed and replaced by fibrous and fatty tissue. Most of the few remaining muscle fibers were RRFs. Specimens from the deltoid and vastus lateralis muscle showed scattered RRFs.

Electron microscopy showed excess mitochondria with pathological inclusions and distorted cristae in the muscle fibers of the extraocular muscles (Fig. $2 b$ ) as well as in the deltoid and vastus lateralis muscles, in the myocardium (Fig. $2 a$ ) and in the tubular epithelium of the
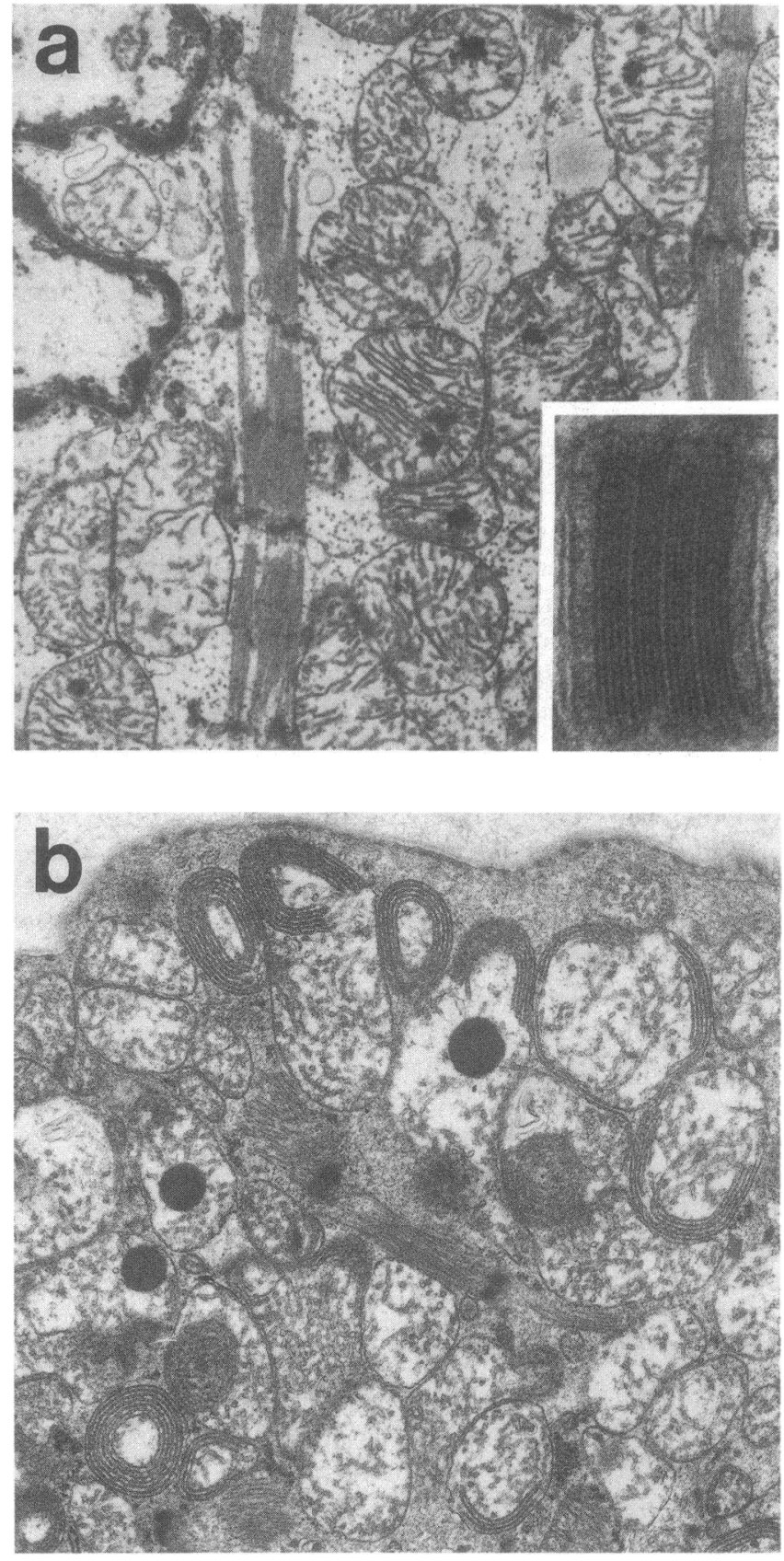

Figure 2. Electron microscopy. ( $a$, inset). Vastus lateralis muscle. Parking lot-type inclusion body in a mitochondrion. Electron micrograph of a biopsy specimen. $\times 100,000$. (a) Heart muscle. The bulk of a heart muscle cell consists of numerous mitochondria many of which harbor electron-dense dot-like inclusions. Myofilaments are scanty. Electron micrograph of an autopsy specimen. $\times 13,500$. (b) Extraocular muscle. The muscle fiber is packed with abnormal mitochondria showing concentric membranous structures and round electron-dense inclusion bodies. Electron micrograph of an autopsy specimen. $\times 13,500$.

kidney. Even some brain cells exhibited abundant mitochondria, occasionally with electron-dense dotlike inclusions.

\section{Biochemical analysis}

Mitochondria were isolated (13) from the patient's autopsy samples of the vastus lateralis and deltoid muscles as well as the kidney and heart within $5 \mathrm{~h}$ after death. The activities of respiratory chain enzymes (ro- 
tenone-sensitive NADH:cytochrome $c$ reductase [14], antimycin-sensitive succinate:cytochrome $c$ reductase [15], succinate dehydrogenase [16], cyanide-sensitive ferrocytochrome $c$ oxidase [17]) were assayed spectrophotometrically from mitochondrial preparations as previously described (14-17). As controls we employed mitochondria from diagnostic muscle biopsies showing no morphological abnormalities from patients who were eventually found not to have muscle diseases, as well as two autopsies of such patients, studied within $5 \mathrm{~h}$ after death.

\section{DNA extraction and Southern analysis}

The muscle biopsy specimens of the patient were immediately frozen in liquid nitrogen. A fresh peripheral blood sample with EDTA as anticoagulant was stored at $-20^{\circ} \mathrm{C}$. The autopsy samples were snap-frozen in liquid nitrogen $3 \mathrm{~h}$ postmortem. Muscle tissue samples derived from abdominal or orthopedic surgery of 20 control individuals with no signs of muscle disease were frozen in liquid nitrogen and studied as described.

Total DNA from the muscle biopsy, leukocytes, and the tissues derived from the autopsy (the cerebral frontal cortex, basal ganglia, heart, kidney, liver, as well as vastus lateralis and extraocular muscles) was extracted as previously described (18). About $3 \mu \mathrm{g}$ of DNA was digested with restriction enzyme PvulI, which cleaves the mtDNA at a single position (nucleotide [nt] 2652 in the mtDNA map [19]) linearizing the circular molecule. The samples were subjected to electrophoresis through $0.6 \%$ agarose gel and transferred to nylon membranes (Hybond-N, Amersham, Bucks., UK) according to Southern (20). The probe, an mtDNA fragment corresponding to the mtDNA map nt 4122-5274 (K6), cloned in pTZ19, was chosen, because it is located in the region between the origins of replication of the molecule and not likely to be deleted. The probe was labeled with $\left[{ }^{32} \mathrm{P}\right] \mathrm{GTP}$ by the random-primer method (21) to a specific activity of $1 \times 10^{9} \mathrm{dpm} / \mu \mathrm{g}$. Prehybridization and hybridization were carried out in $7.5 \%$ dextran sulphate solution, $65^{\circ} \mathrm{C}$ overnight. Further localization of the deletions was carried out using short sequences of human mtDNA in the vectors pTZ18 or pTZ19 as probes (a generous gift from Dr. Nils-Göran Larsson, Gothenburg University, Sweden). The fragments corresponded to the following segments of mtDNA (19): nt 1-740 (K3), nt 5275-6204 (K7), nt 7441-8287 (K9), nt 8287-8592 (K10), nt 8729-10254 (K12), nt 10254-11922 (K13) and nt 11922-12641 (K14).

The proportions of the normal and mutated mtDNA were measured using Ultroscan Laser Densitometer 2202 (LKB Produkter, Bromma, Sweden), on autoradiographs of hybridizations with probe $\mathrm{K} 6$, a short fragment common to both deleted and normal mtDNA allowing optimal quantitation.

\section{Polymerase chain reaction $(P C R)$ analysis}

The oligonucleotides flanking the suspected deletion breakpoints were synthesized on a model 381A DNA synthesizer (Applied Biosystems, Inc., Foster City, CA). The upstream primer included the restriction site for the enzyme ApaI (nt 8249) and the downstream primers the sites for TaqI (nt 14967) and StuI (nt 13705). DNA (100 ng) was amplified (22) with the primers at $1 \mu \mathrm{M}$ and the dNTPs at $0.2 \mathrm{mM}$ concentrations, using 2.0 U of Taq-polymerase (Promega Corp., Madison, WI) in $100 \mu \mathrm{l}$ of its buffer. The reaction conditions on a programmable heating block (model $\mathrm{PHCl}$, Techne, Inc., Princeton, $\mathrm{NJ}$ ) were as follows: $94^{\circ} \mathrm{C} 1.5 \mathrm{~min}, 55^{\circ} \mathrm{C} 2 \mathrm{~min}, 72^{\circ} \mathrm{C} 3 \mathrm{~min}, 30$ cycles.

\section{Results}

DNA analyses. In the preliminary Southern hybridization analysis of mitochondrial DNA of the patient we found several hybridizing signals in the samples derived from the cerebral frontal cortex, basal ganglia, heart, kidney, and liver as well as the vastus lateralis and extraocular muscles (Fig. 3). In addition to the normal 16.6-kb mtDNA population we observed several smaller, faster-migrating populations of $\mathrm{mtDNA}$ ranging from $\sim 14.5$ to $6.5 \mathrm{~kb}$ corresponding to deletions from $\sim 2.0$ to 10.0 $\mathrm{kb}$, respectively. Many of the signals were identical in different

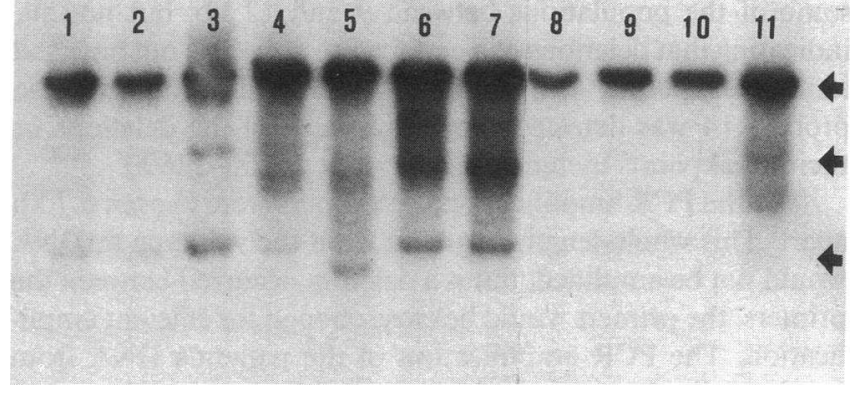

Figure 3. Southern blot analysis of the mitochondrial DNA (mtDNA). The patients total DNA from lane 1, kidney; lane 2, liver; lane 3, heart; lane 4, extraocular muscle; lane 5 , vastus lateralis muscle; lane 6, basal ganglia; lane 7, cerebral frontal cortex; lane 8 , leukocytes. Lanes 9 and 10, healthy control individuals; lane 11 , muscle DNA from the patient's affected sister. The arrows indicate the molecular weight (from the top): $16.6,9.4$, and $6.6 \mathrm{~kb}$. A cloned fragment (mitochondrial map position nt 4122-5274) of mtDNA was used as the hybridization probe and several hybridizing signals were detected. The 16.6-kb signals correspond to the normal mtDNA population. The faster moving signals of $\sim 14.5-6.5 \mathrm{~kb}$ correspond to deleted mtDNA populations.

tissues. Only the $16.6-\mathrm{kb}$ signal was consistently detected in the samples of all 20 control individuals as well as in the leukocyte DNA of the patient. The proportion of the normal mtDNA was lowest, $\sim 40 \%$, in the basal ganglia, frontal cortex and vastus lateralis muscle whereas the kidneys contained about $90 \%$ normal mtDNA (Fig. 4).

The mtDNA deletions were localized using short sequences of mtDNA as hybridization probes. All the bands detected in the Southern blot analysis hybridized with the probes K3, K6, and $\mathrm{K} 7$ indicating that these areas were conserved in the deleted mtDNA populations. The probes $\mathrm{K} 9$ and $\mathrm{K} 10$ hybridized with the populations $>9 \mathrm{~kb}$, but the signals of lower molecular weight disappeared. The probes K12 and K13 hybridized with

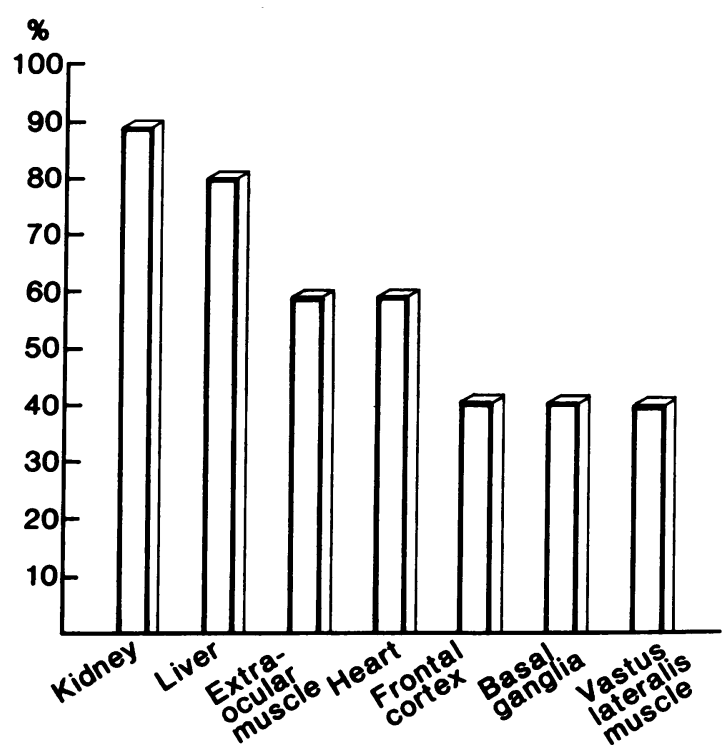

Figure 4. Densitometry of the Southern analysis. The bars in the histogram indicate the percentage of normal mtDNA of total mtDNA in each tissue. 
some of the populations between 9 and $12 \mathrm{~kb}$, but not all, indicating that deletions of a certain size range did not have the same breakpoints. Only faint or no hybridization with the probe $\mathrm{K} 14$ was detected suggesting most of the deletions or their breakpoints include the area of nt 11900-12600.

For the PCR amplification the primers were chosen $6.7 \mathrm{~kb}$ apart. This whole-length fragment from the wildtype mtDNA would not be amplified, but if a deletion occurred between the primers, the primers would be close enough for efficient amplification. The PCR amplification of the patient's DNA from basal ganglia, frontal cortex, vastus lateralis, heart, and extraocular muscles (Fig. 5) with the primers Apa 8.2 and Taq 14.9 resulted in 10-15 fragments ranging from 2.0 to $0.2 \mathrm{~kb}$. These fragments corresponded to mtDNA deletions of 4.7-6.5 kb, respectively. Amplification of leukocyte DNA did not result in any product. The tissues shared many of the amplifying fragments so, that the samples of different parts of the brain were very similar, and the different muscles shared several bands. Amplification of mtDNA from healthy controls did not show any product (Fig. 5). The corresponding 6.7-kb fragment from the wild-type mtDNA was not detected. To still ascertain the PCR finding, another downstream primer, Stu 13.7, was used. Amplification of the patient's samples with the primers Apa 8.2 and Stu 13.7 also resulted in several fragments.

The deletions were localized to the region containing the genes that encode the subunit II and III of cytochrome $c$ oxidase, subunit VI and VIII of ATPase, and the subunits III, IV, $\mathrm{V}$, and VI of NADH-dehydrogenase as well as several tRNA genes. Amplification products with the primers Apa 8.2 and Taq 14.9 or Stu 13.7 showed that several of the deletion breakpoints were in coding regions, in the genes encoding the cytochrome $b$, the subunit $\mathrm{V}$ of NADH-dehydrogenase or upstream from them.

\section{$\begin{array}{llllllllllll}1 & 2 & 3 & 4 & 5 & 6 & 7 & V I & 8 & 9 & 10 & \text { VI }\end{array}$}

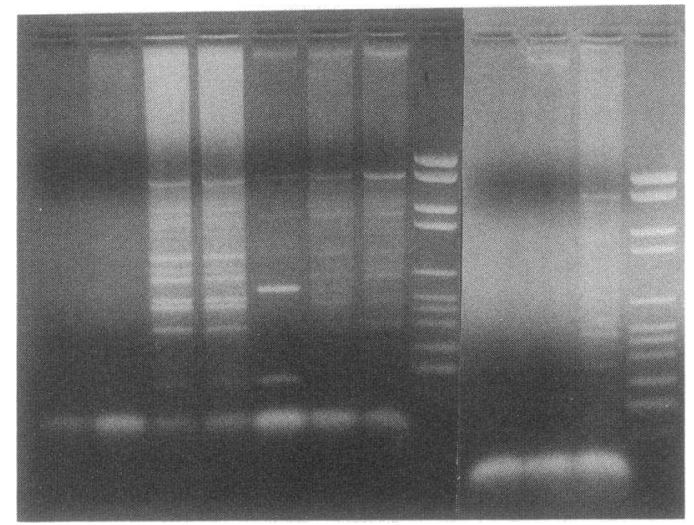

Figure 5. Polymerase chain reaction-analysis. Lanes 1 and 9 , healthy control individuals. The patient's DNA from lane 2, leukocytes; lane 3 , basal ganglia; lane 4, cerebral frontal cortex; lane 5, extraocular muscle; lane 6 , vastus lateralis muscle; lane 7 , heart. Lane 8 , water control; lane 10, the patient's affected sister, muscle DNA. DNA was amplified using primers Apa 8.2 and Taq 14.9. 10-15 amplification products ranging from 2.0 to $0.2 \mathrm{~kb}$ were detected in all the other tissue samples except the leukocyte samples of the patient, corresponding to the deletions of 4.7-6.5 kb, respectively. Also, the muscle DNA sample of the patient's affected sister showed several PCR products. The molecular weight marker VI (Boehringer, Mannheim, FRG) was pBR328 DNA cut with BglI and HindI (fragment sizes 2176, 1766, $1230,1033,653,517,453,394,298,234$, and $220 \mathrm{bp}$ ).
The Southern blot and PCR analyses of muscle mtDNA of the patient's affected sister (Figs. 3 and 5) as well as of the other affected siblings showed multiple deletions of mtDNA. Muscle biopsies from the healthy members of the family were not available. PCR analysis of leukocyte DNA did not reveal deletions either in affected or healthy members of the family (Fig. 5).

Biochemistry. Biochemical analysis of the skeletal muscle mitochondria showed a marked respiratory chain defect affecting mtDNA encoded enzymes but not succinate dehydrogenase (Table I). The rotenone-sensitive NADH:cytochrome $c$ reductase was most severely affected followed by cytochrome $c$ oxidase and antimycin-sensitive succinate:cytochrome $c$ reductase. The respiratory chain enzyme activities of the myocardial and kidney tissue of the patient were comparable to controls except for the elevated succinate dehydrogenase activity in both tissues. In the myocardium the activity of the NADH:cytochrome $c$ reductase was slightly reduced.

\section{Discussion}

The RRFs in the muscle biopsy sample and the family history of PEO with autosomal dominant transmission encouraged us to study the mitochondrial DNA of our patient's muscle. We detected multiple deletions of mtDNA in her muscle biopsy sample as well as in the muscle biopsy specimens of her affected siblings. Therefore the case was regarded as an autosomal dominant PEO with multiple deletions of mtDNA (6-8). Postmortem study showed that the disease was not only a myopathy, but a multisystem disorder.

We analyzed the patient's samples from the brain, heart, skeletal muscle, liver, and kidney, and found multiple deletions of mtDNA in all the tissues. No deletions were detected in the leukocyte mtDNA of the patient either by Southern blot or by PCR. Previously, multiple deletions have been found only

Table I. Enzyme Activities in Isolated Mitochondria

\begin{tabular}{lcccc}
\hline & SDH $^{*}$ & NADH:cyt $c^{ \pm}$ & Succ:cyt $c^{8}$ & COX" $^{\prime \prime}$ \\
\hline Vastus & \multicolumn{5}{c}{ nmol/min per mg mitochondrial protein } \\
$\quad$ lateralis & 171 & 10.2 & 35.6 & 206 \\
Deltoid & & & & \\
$\quad$ muscle & 330 & 29.8 & 115 & 800 \\
Controls & $181 \pm 54$ & $295 \pm 91$ & $276 \pm 97$ & $2620 \pm 858$ \\
& $(16)$ & $(32)$ & $(37)$ & $(10)$ \\
Heart & 324 & 171 & 273 & 1390 \\
Controls & 273 & 447 & 301 & 2520 \\
& 171 & 196 & 179 & 1350 \\
Kidney & 279 & 127 & 333 & 855 \\
Controls & 218 & 145 & 410 & 953 \\
& 103 & 104 & 292 & 944 \\
& & & & \\
\hline
\end{tabular}

Activities correspond to reduced or oxidized cytochrome $c$ and reduced 2,6-dichlorophenolindophenol. The control values of muscle tissue (vastus lateralis muscle) are mean $\pm \mathrm{SD}$; number of controls in parentheses. The control values of the heart and kidney tissues are from original measurements. * Succinate dehydrogenase. ${ }^{ \pm}$NADH: cytochrome $c$ reductase. "Succinate:cytochrome $c$ reductase. "Cytochrome $c$ oxidase. 
in the muscle tissue $(6-9,11)$ and leukocytes $(10)$. Our Southern blot finding closely resembled the Italian cases (6-8) showing many deletions of different sizes. In the Italian families, the mtDNA was analyzed from muscle tissue, leukocytes, and fibroblasts and only muscle showed multiple deletions. This suggested that the deletions might be tissue specific (8). In our patient, although no signs of a multisystem disorder were detected in the patient's lifetime, the deletions were present in most tissues.

Our patient had typical PEO. However, the major clinical symptom throughout her adult life was severe retarded depression. Three depressive episodes were treated before the PEO became evident. All the episodes, including those in the later phase of her life, were very similar, extreme retardation being the specific feature of the depression. However, between these episodes the patient was working and considered healthy. Because the predominant symptoms were psychiatric, the autopsy specimens were taken from different parts of the brain. MtDNA was analyzed from frontal cortex and basal ganglia specimens and multiple deletions were found in both samples studied. Ciafaloni et al. (23) reported a family in which the mother and daughter had PEO and affective disorder with multiple deletions of mtDNA in muscle tissue. The brain tissue was not studied in their cases. The other affected members of our patient's family have a depressive tendency, although the proband was the only one receiving psychiatric treatment. Our findings suggest that the multiple deletions of mtDNA in the brain tissue and the development of a depressive disorder may be connected. However, further studies are needed to confirm this finding.

The patient did not have any symptoms of liver or kidney disease, which were the organs with the lowest percentage of mutated mtDNA. Before the terminal phase she was not known to suffer from any cardiac disease although only $60 \%$ of the mtDNA of the heart appeared to be normal. However, the patient died due to cardiac arrhythmia after two resuscitation events and no sign of myocardial infarct was detected in the autopsy.

The biochemical analysis of the mitochondria of the skeletal muscle showed a remarkable reduction in the activities of the respiratory chain enzymes partially encoded by mtDNA. The residual activities of these enzymes were only $10-20 \%$ of the controls' means in the skeletal muscle that harbored $60 \%$ of mutated mtDNA, whereas the heart with $40 \%$ of mutated genomes showed only minor reductions in the activities. Servidei et al. (8) reported reduction of the activity of succinate dehydrogenase, which is encoded by nuclear genes, in the muscle homogenates from the patients with familial PEO. In our patient the activity of succinate dehydrogenase in isolated mitochondria was in the normal range in the muscle, and elevated both in the heart and kidney. This could be due to compensatory increase in the production of the respiratory chain enzymes encoded by the nucleus and the proliferation of the mitochondrial inner membrane.

The Southern blot analysis with short cloned sequences of mtDNA as probes mapped the $5^{\prime}$ breakpoints of the deletions to the region starting from the gene encoding subunit II of cytochrome c oxidase. The PCR amplifications with the downstream primers in the genes encoding the cytochrome $b$ (Taq 14.9) and the subunit V of NADH dehydrogenase (Stu 13.7) showed that several of the 3 '-breakpoints are localized in those genes or upstream from them. This confirms the recent reports (7-11) that all the deletions do not originate from the displacement loop region of mtDNA as previously reported (6).

The pattern of inheritance in our pedigree was regarded as autosomal dominant because of the transmission of the disease from father to son. This suggests that a mutation in a nuclear gene results in multiple deletions of mtDNA. This gene could encode for a protein involved in the replication of mtDNA $(6-8)$. The defect in this protein could make mtDNA susceptible to strand slippage and mispairing (24) resulting in deletions. The candidate could be for example a protein preventing the DNA branch migration during the heavy strand formation $(7,25)$.

Our Southern blot and PCR analyses demonstrate that the deletions are often identical in different tissues and that two patients share several bands. Previous reports (6-10, 24, 2628 ) show that the deletions are usually flanked by short sequence repeats. These areas are deletion "hot spots" and could be susceptible to abnormal branch migration. Another still more hypothetical theory is that a deleterious external factor hits the hot spots of mtDNA causing deletions. There has recently been speculation on the role of free radicals in the accumulation of mtDNA mutations, in connection with the process of ageing (29). We observed a suggestive association between the amount of deleted molecules and the rate of oxidative metabolism of the tissue. In the patient, the brain and the heart as well as the skeletal and extraocular muscles, tissues highly dependent on oxygen, also demonstrate high numbers of deleted genomes.

The patient described here with a clinical diagnosis of autosomal dominant PEO actually suffered from a multisystem disorder with multiple deletions of mtDNA in several tissues. It is possible that the familial PEO reported previously $(6-8)$ is a mild variant of this disorder, which in our patient expresses itself by affecting the brain, heart, and muscle. However, the clinical and biochemical features are partially different in the reported families, which suggests heterogeneity within the diagnosis of dominantly inherited disorder with multiple deletions of mtDNA. The search for the still hypothetical nuclear mutation is necessary for understanding the pathogenesis of the disease and, finally, the interaction between the nucleus and the mitochondria.

\section{Acknowledgments}

This work was supported by the grants derived from The Research Foundation of Neuromuscular Diseases, Arvo and Lea Ylppö Foundation, The Foundation of Finnish Medicine, Emil Aaltonen Foundation, and Sigrid Juselius Foundation.

\section{References}

1. Holt, I. J., A. E. Harding, and J. A. Morgan-Hughes. 1988. Deletions of muscle mitochondrial DNA in patients with mitochondrial myopathies. Nature (Lond.). 331:717-719.

2. Ozawa, T., M. Yoneda, M. Tanaka, K. Ohno, W. Sato, H. Suzuki, M. Nishikimi, M. Yamamoto, I. Nonaka, and S. Horai. 1988. Maternal inheritance of deleted mitochondrial DNA in a family with mitochondrial myopathy. Biochem. Biophys. Res. Commun. 154:1240-1247.

3. Moraes, C. T., S. DiMauro, M. Zeviani, A. Lombes, S. Shanske, A. F. Miranda, H. Nakase, E. Bonilla, L. C. Werneck, S. Servidei, et al. 1989. Mitochondrial DNA deletions in progressive external ophthalmoplegia and KearnsSayre syndrome. N. Engl. J. Med. 320:1293-1299. 
4. Zeviani, M., C. T. Moraes, S. DiMauro, H. Nakase, E. Bonilla, E. A. Schon, and L. P. Rowland. 1988. Deletions of mitochondrial DNA in Kearns-Sayre syndrome. Neurology. 38:1339-1346.

5. Rötig, A., M. Colonna, J. P. Bonnefont, S. Blanche, A. Fisher, J.-M. Saudubray, and A. Munnich. 1989. Mitochondrial DNA deletion in Pearson's marrow/ pancreas syndrome. Lancet. 1:902-903.

6. Zeviani, M., S. Servidei, C. Gellera, E. Bertini, S. DiMauro, and S. DiDonato. 1989. An autosomal dominant disorder with multiple deletions of mitochondrial DNA starting at the D-loop region. Nature (Lond.). 339:309-311.

7. Zeviani, M., N. Bresolin, C. Gellera, A. Bordoni, M. Pannacci, P. Amati, M. Moggio, S. Servidei, G. Scarlato, and S. DiDonato. 1990. Nucleus-driven multiple large-scale deletions of the human mitochondrial genome: a new autosomal dominant disease. Am. J. Hum. Genet. 47:904-914.

8. Servidei, S., M. Zeviani, G. Manfredi, E. Ricci, G. Silvestri, E. Bertini, C. Gellera, S. DiMauro, S. DiDonato, and P. Tonali. 1991. Dominantly inherited mitochondrial myopathy with multiple deletions of mitochondrial DNA: clinical, morphologic and biochemical studies. Neurology. 41:1053-1059.

9. Yuzaki, M., N. Ohkoshi, I. Kanazawa, Y. Kagawa, and S. Ohta. 1989. Multiple deletions in mitochondrial DNA at direct repeats of non-D-loop regions in cases of familial mitochondrial myopathy. Biochem. Biophys. Res. Commun. 164:1352-1357.

10. Cormier, V., A. Rötig, M. Tardieu, M. Colonna, J.-M. Saudubray, and A. Munnich. 1991. Autosomal dominant deletions of the mitochondrial genome in a case of progressive encephalomyopathy. Am. J. Hum. Genet. 48:643-648.

11. Ohno, K., M. Tanaka, K. Sahashi, T. Ibi, W. Sato, T. Yamamoto, A. Takahashi, and T. Ozawa. 1991. Mitochondrial DNA deletions in inherited recurrent myoglobinuria. Ann. Neurol. 29:364-369.

12. Poulton, J., M. E. Deadman, S. Ramacharan, and R. M. Gardiner. 1991. Germ-line deletions of mtDNA in mitochondrial myopathy. Am. J. Hum. Genet. 48:649-653.

13. Bookelman, H., J. M. F. Trijbels, R. C. A. Sengers, A. J. M. Jansson, J. H. Veerkamp, and A. M. Stadhouders. 1978. Pyruvate oxidation in rat and human skeletal muscle mitochondria. Biochem. Med. 20:395-403.

14. Fischer, J. C., W. Ruitenbeek, J. M. F. Trijbels, J. H. Veerkamp, A. M. Stadhouders, R. C. A. Sengers, and A. J. M. Janssen. 1986. Estimation of NADH oxidation in human skeletal muscle mitochondria. Clin. Chim. Acta. 155:264274.

15. Fischer, J. C., W. Ruitenbeek, J. A. Berden, J. M. F. Trijbels, J. H. Veerkamp, A. M. Stadhouders, R. C. A. Sengers, and A. J. M. Janssen. 1985. Differential investigation of the capacity succinate oxidation in human skeletal muscle. Clin. Chim. Acta. 153:23-36.
16. Ackrell, B. A. C., E. B. Kearney, and T. P. Singer. 1978. Mammalian succinate dehydrogenase. Methods Enzymol. 53:466-483.

17. Wharton, D. C., and A. Tzagoloff. 1967. Cytochrome oxidase from beef heart mitochondria. Methods Enzymol. 10:245-250.

18. Davis, L. G., M. D. Dibner, and J. F. Battey. 1986. In Basic Methods in Molecular Biology. P. Leder, editor. Elsevier Science Publishing Co., Inc., New York. 47-50.

19. Anderson, S., A. T. Bankier, B. G. Barrell, M. H. L. de Bruijn, A. R. Coulson, J. Drouin, I. C. Eperon, D. P. Nierlich, B. A. Roe, F. Sanger, et al. 1981. Sequence and organization of the human mitochondrial genome. Nature (Lond.). 290:457-465.

20. Southern, E. M. 1975. Detection of specific sequences among DNA fragments separated by gel electrophoresis. J. Mol. Biol. 98:503-515.

21. Feinberg, A. P., and B. Vogelstein. 1984. A technique for radiolabelling restriction endonuclease fragments to high specific activity. Anal. Biochem. 137:266-267.

22. Saiki, R. K., D. H. Gelfand, S. Stoffel, S. J. Sharf, R. Higuchi, G. T. Horn, K. B. Mullis, and H. A. Erlich. 1988. Primer-directed enzymatic amplification of DNA with a thermostable DNA polymerase. Science (Wash. DC). 239:487-491.

23. Ciafaloni, E., S. Shanske, S. Apostolski, R. L. Griggs, T. D. Bird, M. Sumi, and S. DiMauro. 1991. Multiple deletions of mitochondrial DNA. Neurology. 41:323P. (Abstr.)

24. Shoffner, J. M., M. T. Lott, A. S. Voljavec, S. A. Soueidan, D. A. Costigan, and D. C. Wallace. 1989. Spontaneous Kearns-Sayre/chronic external ophthalmoplegia plus syndrome associated with a mitochondrial DNA deletion: a slip-replication model and metabolic therapy. Proc. Natl. Acad. Sci. USA. 86:79527956.

25. Clayton, D. A. 1982. Replication of animal mitochondrial DNA. Cell. 28:693-705.

26. Schon, E. A., R. Rizzuto, C. T. Moraes, H. Nakase, M. Zeviani, and S. DiMauro. 1989. A direct repeat is a hotspot for large-scale deletion of human mitochondrial DNA. Science (Wash. DC). 244:346-349.

27. Johns, D. R., S. L. Rutledge, O. C. Stine, and O. Hurko. 1989. Directly repeated sequences associated with pathogenic mitochondrial DNA deletions. Proc. Natl. Acad. Sci. USA. 86:8059-8062.

28. Mita, S., R. Rizzuto, C. T. Moraes, S. Shanske, E. Arnaudo, G. M. Fabrizi Y. Koga, S. DiMauro, and E. A. Schon. 1990. Recombination via flanking direct repeats is a major cause of large-scale deletions of human mitochondrial DNA Nucleic Acids Res. 18:561-567.

29. Cortopassi, G. A., and N. Arnheim. 1990. Detection of a specific mitochondrial DNA deletion in tissues of older humans. Nucleic Acids Res. 18:69276933. 